\title{
Ultrasound guidance to facilitate low interscalene brachial plexus block in a patient with indwelling hemodialysis catheter
}

\author{
Thomas Maliakal, MD · Seema Patel, DO • \\ Admir Hadzic, MD, PhD
}

Received: 27 March 2009/Accepted: 9 April 2009/Published online: 28 April 2009

(C) Canadian Anesthesiologists' Society 2009

\section{To the Editor,}

Interscalene brachial plexus block (IBPB) is an effective anesthesia technique for patients having upper extremity vascular access procedures. ${ }^{1,2}$ Traditional IBPB without visualization of the anatomy may prove challenging or carry a risk of injury to the existing hemodialysis access devices in patients with end-stage renal disease. In this letter, we communicate the value of ultrasound guidance to accomplish a successful IBPB while reducing the risk of puncturing an indwelling hemodialysis catheter.

A 58-year-old patient with American Society of Anesthesiologist's physical status classification (ASA) III was scheduled for a right upper extremity arteriovenous graft placement. Her medical history was significant for hypertension, insulin dependent diabetes mellitus, hypercholesterolemia, previous myocardial infarction, and endstage renal disease on hemodialysis through right-sided Permacath $^{\mathrm{TM}}$. Physical examination over the area of needle insertion for the low interscalene-supraclavicular brachial plexus block revealed palpable tumescence due to the course of the hemodialysis catheter. Additionally, significant scar tissue, due to previous internal jugular catheterization for hemodialysis, made palpation of the relevant anatomy difficult. The patient was positioned semi-supine, was administered oxygen via mask $\left(4 \mathrm{~L} \cdot \mathrm{min}^{-1}\right)$, and was monitored using standard ASA monitors ( $\mathrm{SpO} 2$, electrocardiogram, NIBP). After premedication with midazolam $3 \mathrm{mg} i v$, fentanyl $50 \mu \mathrm{g} i v$ and cefazolin $1 \mathrm{~g} i v$ a linear array ultrasound probe (LOGIQe equipped with $12 \mathrm{~L}$ transducer; General Electric, Milwaukee, WI, USA) was applied over the patient's lower neck. The central venous catheter (CVC) was readily identified by the acoustic shadow (Fig. 1). After localizing the nerve, a Stimuplex ${ }^{\circledR}$ Insulated needle (50 mm, 22G, B-Braun, Bethlehem, Germany) was placed in long axis with the ultrasound probe and advanced towards the brachial plexus while avoiding the central venous catheter. Proper needle placement was confirmed simultaneously by biceps motor response at $0.45 \mathrm{~mA}$ (Stimuplex ${ }^{\circledR}$ Dig RC, B. Braun Melsungen AG). The patient was administered 0.5\% ropivacaine $20 \mathrm{~mL}$ in $5 \mathrm{~mL}$ increments with negative aspiration, resulting in successful and uneventful anesthesia and surgery.

Major causes of central venous catheter dysfunction are thrombosis (of the catheter or vessel itself), fibrin sheath formation, and infection. ${ }^{1,2}$ The pathogenesis of CVCrelated thrombosis is multifactorial; however, any injury to the vascular endothelium or the catheter itself during the block carries a risk of thrombosis. In addition to suboptimal flow rates, pulmonary embolism occurs in $15-25 \%$ of patients with symptomatic CVC-related thrombosis. ${ }^{3,4}$

In summary, similar to patients with ventriculoperitoneal shunts, ${ }^{5}$ ultrasound guidance can also be used to accomplish a successful IBPB and to reduce the risk of injury to hemodialysis access devices in patients with endstage renal disease.

Conflicts of interest None declared.

T. Maliakal, MD - S. Patel, DO - A. Hadzic, MD, PhD (ه)

St. Luke's-Roosevelt Hospital Center, Columbia University

College of Physicians and Surgeons, New York, USA

e-mail: admir@nysora.com 


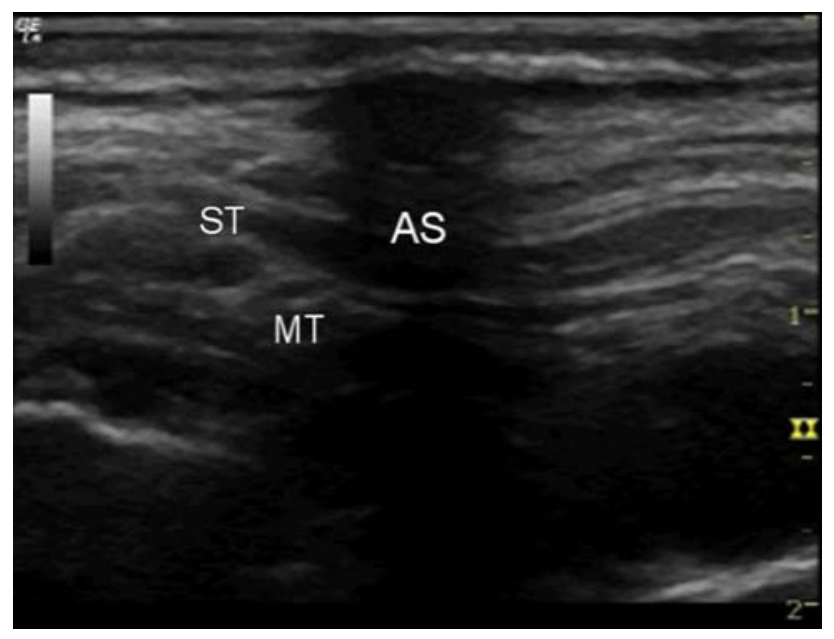

Fig. 1 Acoustic shadow in close proximity to the trunks of the brachial plexus. $A S$ acoustic shadow, $S T$ superior trunk, $M T$ middle trunk

\section{References}

1. Forauer AR, Theoharis $C$. Histologic changes in the human vein wall adjacent to indwelling central venous catheters. J Vasc Interv Radiol 2003; 14: 1163-8.

2. Oguzkurt L, Tercan F, Torun D, Yildirim T, Zumrutdal A, Kizilkilic $O$. Impact of short-term hemodialysis catheters on the central veins: a catheter venographic study. Eur J Radiol 2004; 52: 293-9.

3. Monreal M, Lafoz E, Ruiz J, Valls R, Alastrue A. Upper-extremity deep venous thrombosis and pulmonary embolism. A prospective study. Chest 1991; 99: 280-3.

4. Monreal M, Raventos A, Lerma R, et al. Pulmonary embolism in patients with upper extremity DVT associated to venous central lines-a prospective study. Thromb Haemost 1994; 72: 548-50.

5. Robards CB, Iwata $T$, Somasundaram $L, X u$ D, Hadzic A. Ultrasound-guided interscalene brachial plexus block in a patient with a ventriculoperitoneal shunt. Reg Anesth Pain Med 2008; 33: $273-4$. 